\title{
Site Specific Deposition of Iron Particles for Carbon Nanotube Growth
}

\author{
See Wee Chee*, Chase Yurga-Bell ${ }^{+}$and Renu Sharma* \\ * LeRoy Eyring Center for Solid State Science, ${ }^{+}$School of Materials, Arizona State University, \\ Tempe, AZ 85287-9506
}

Carbon nanotubes (CNT) are promising material for making electron field emission sources but one of the key challenges is the synthesis of arrays of nanotubes with controlled size and placement. Recently, we reported the site-specific deposition of Fe catalyst particles using electron beam induced deposition (EBID) in an environmental scanning/transmission electron microscope $(\mathrm{E}(\mathrm{S}) \mathrm{TEM})[2]$. In addition, the column of the ETEM was also used as a reactor for CNT growth from these particles to directly observe the nucleation and growth processes with atomic resolution [3]. However, the relationship between various EBID and CNT growth parameters is still not resolved. In this paper, we present the reactivity of iron particles deposited by EBID using two different organometallic compounds, diiron nonacarbonyl $\left(\mathrm{Fe}_{2}(\mathrm{CO})_{9}\right)$ and ferrocene $\left(\mathrm{Fe}\left(\mathrm{C}_{5} \mathrm{H}_{5}\right)_{2}\right.$.

A Tecnai F20 E(S)TEM is used for both EBID and growth of CNTs. Perforated $\mathrm{SiO}_{2}$ films on Si wafers are used as substrate. The inlet gas pressure was kept around 0.4 to 0.8 mTorr and deposition times from $5 \mathrm{~s}$ to $30 \mathrm{~s}$ were used. The Fe containing particles were then heated in $100 \mathrm{mTorr}$ of hydrogen up to $650{ }^{\circ} \mathrm{C}$ before introducing acetylene for CNT growth. Electron energy loss spectroscopy (EELS) data were also collected from the deposited particles before and after heating in hydrogen.

Figure 1 shows the size distribution of a series particles deposited using $\mathrm{Fe}_{2}(\mathrm{CO})_{9}$ (left) and $\mathrm{Fe}\left(\mathrm{C}_{5} \mathrm{H}_{5}\right)_{2}$ (right). The Fe particle size and $\mathrm{Fe}$ to background ratio from the EELS spectra for deposition temperatures of $60^{\circ} \mathrm{C}$ and $100^{\circ} \mathrm{C}$ are summarized in table 1 . While the particle size is similar $(\sim 10 \mathrm{~nm})$ for both $\mathrm{Fe}_{2}(\mathrm{CO})_{9}$ and $\mathrm{Fe}\left(\mathrm{C}_{5} \mathrm{H}_{5}\right)_{2}$ at $60^{\circ} \mathrm{C}$ but the amount of $\mathrm{Fe}$ deposited is much smaller from $\mathrm{Fe}\left(\mathrm{C}_{5} \mathrm{H}_{5}\right)_{2}$. At $100^{\circ} \mathrm{C}$, there is a small decrease in size for $\mathrm{Fe}_{2}(\mathrm{CO})_{9}$ but almost no noticeable deposition for $\mathrm{Fe}\left(\mathrm{C}_{5} \mathrm{H}_{5}\right)_{2}$ at the same duration of $15 \mathrm{~s}$. In addition, the EELS spectra show that a greater amount of carbon is incorporated into the particles deposited from $\mathrm{Fe}\left(\mathrm{C}_{5} \mathrm{H}_{5}\right)_{2}$ (Figure 2, middle spectra) compared to the ones from $\mathrm{Fe}_{2}(\mathrm{CO})_{9}$ (Figure 2, lower spectra). Carbon content in these particles deceased upon heating in hydrogen (Figure 2, top spectra).

We find that CNT grow from the Fe particles grown from both precursors, but the number of particles deposited using $\mathrm{Fe}_{2}(\mathrm{CO})_{9}$ active for $\mathrm{CNT}$ growth is higher compared to the ones deposited using $\mathrm{Fe}\left(\mathrm{C}_{5} \mathrm{H}_{5}\right)_{2}$. A detailed analysis particle size with precursor pressure, deposition time and temperature along with the structural and morphological changes that takes place in these particles during CNT growth will be also be presented.

References:

[1] N. de Jonge, J.M. Bonard, Phil. Trans. R. Soc. Lond. A 362 (2004) 2239

[2] R. Sharma et al, Nano Lett. 9 (2009) 689

[3] R. Sharma, J. Mater. Res. 20 (2005) 1695

[4] Funding from NSF-CBET \#0625340. The use of facilities in the LeRoy Eyring Center for Solid State Science at Arizona State University is gratefully acknowledged 

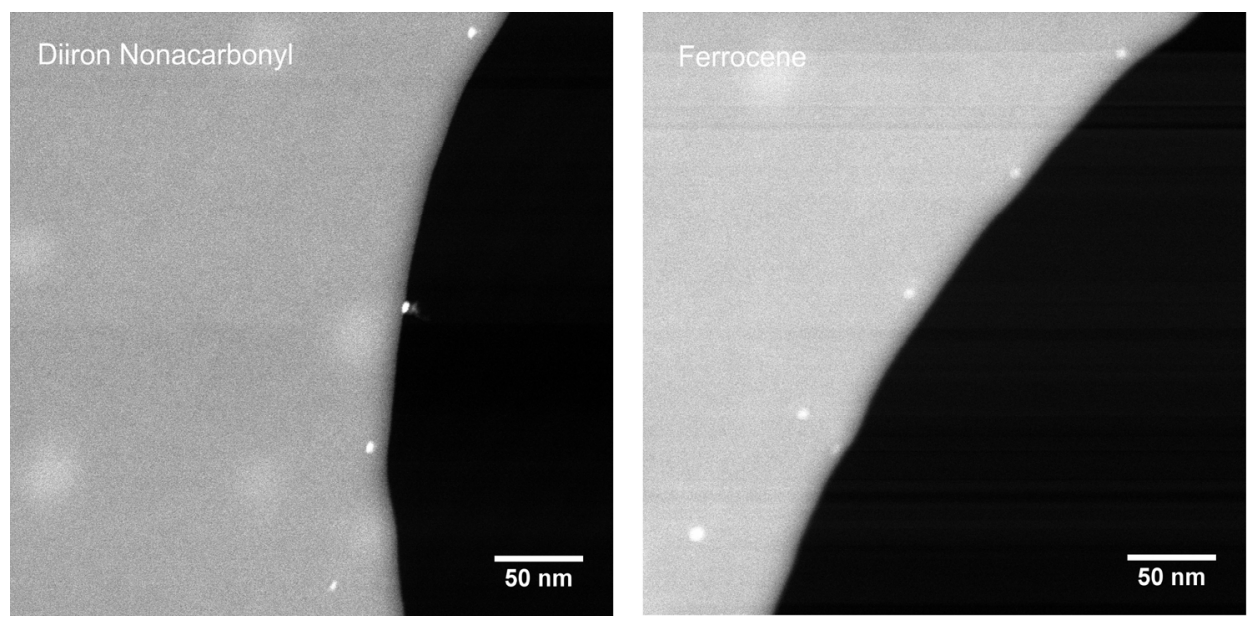

Figure 1. Annular dark field images of Fe particles deposited using diiron nonacarbonyl at $100^{\circ} \mathrm{C}$ (left) and ferrocene at $60^{\circ} \mathrm{C}$ (right)

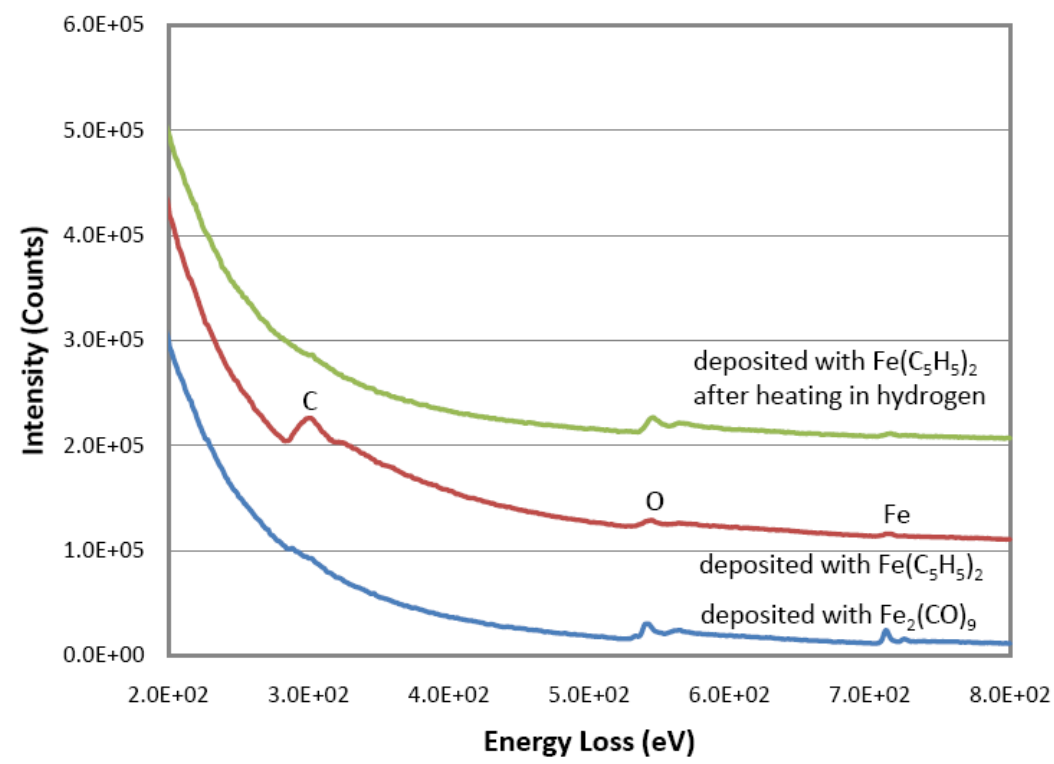

Figure 2. EELS Spectra of diiron nonacarbonyl (lower), ferrocene deposited particle (middle) and ferrocene particle after heating in $\mathrm{H}_{2}$ (top)

Table 1. Comparison of $\mathrm{Fe}$ particle size and $\mathrm{Fe}$ to background ratio from EELS for deposition using diiron nonacarbonyl and ferrocene

\begin{tabular}{llccc}
\hline & \multicolumn{2}{c}{$60^{\circ} \mathrm{C}$} & \multicolumn{2}{c}{$100^{\circ} \mathrm{C}$} \\
\hline & $\begin{array}{c}\text { Fe Particle Size } \\
(\mathrm{nm})\end{array}$ & $\begin{array}{c}\text { Fe to Background } \\
\text { Ratio }\end{array}$ & $\begin{array}{c}\text { Fe Particle Size } \\
(\mathrm{nm})\end{array}$ & $\begin{array}{c}\text { Fe to Background } \\
\text { Ratio }\end{array}$ \\
\hline $\mathrm{Fe}_{2}(\mathrm{CO})_{9}$ & & & & \\
$5 \mathrm{~s}$ & 5.7 & 0.057 & 4.9 & 0.12 \\
$15 \mathrm{~s}$ & 10.3 & 0.18 & 8.7 & 0.27 \\
\hline $\mathrm{Fe}\left(\mathrm{C}_{5} \mathrm{H}_{5}\right)_{2}$ & 10.6 & & & - \\
$15 \mathrm{~s}$ & 12.3 & 0.044 & - & 0.055 \\
$30 \mathrm{~s}$ & 0.034 & 5.6 & \\
\hline
\end{tabular}

